\title{
ESPETÁCULO DESPROVIDO DE ARTE - O TEMA DO LUXO EM ROUSSEAU
}

\author{
Luís Fernandes dos Santos Nascimento ${ }^{1}$
}

Resumo: O presente artigo analisa a atitude peculiar que Rousseau assume na célebre "querela do luxo": diante da valorização do gosto refinado nas artes em um século marcado pelo espírito de galanteria e pelo modelo de vida fútil e pomposa da corte, é na condição de escritor que Rousseau, paradoxal e conscientemente, denuncia os efeitos sociais nocivos do luxo sobre os costumes. Palavras-chave: Rousseau, luxo, artes, ciências.

"Il vit un spectacle que ne donneront jamais vos richesses ni tous vos arts; le plus beau spectacle qui ait jamais paru sous le ciel'

(J-J. Rousseau $\left.{ }^{2}\right)$

Não é estranho ao século XVIII vincular o tema do luxo ao do declínio das artes, do conhecimento, da cultura, da liberdade e da virtude. E ao fazê-lo, esse mesmo século muitas vezes lembra-nos que esse procedimento já estava presente na obra dos antigos. $\mathrm{O}$ britânico Shaftesbury, por exemplo, ao falar do luxo e relacioná-lo à decadência das artes e dos costumes em seu Solilóquio, cita Plínio, o velho ${ }^{3}$. Diderot, no Paradoxo sobre o comediante, ao criticar a pompa e a ostentação do teatro clássico francês, reivindica a simplicidade que reinava no drama antigo ${ }^{4}$. D'Alembert, lembra-nos Victor Goldschmidt, quando critica a faceta perniciosa do luxo, recorre a Xenofonte para afirmar que as artes do agrément (atrativo, encanto, ornato) inspiram o mero gosto pelo prazer, gosto que está próximo "do excesso e da licenciosidade" . Desse ponto de vista, ao introduzir a questão do luxo no Primeiro Discurso, quando lança mão de exemplos da Roma imperial para ilustrar momentos

\footnotetext{
${ }^{1}$ Professor adjunto do Departamento de Filosofia e Metodologia das Ciências da Universidade Federal de São Carlos (DFMC-UFSCar). E-mail: luisfsnascimento@yahoo.com.br.

2 ROUSSEAU, Discours sur les sciences et les arts, p. 15.

3 SHAFTESBURY, "Soliloquy or advice to an author". In: Characteristicks of Men, Manners, Opinions, Times, v. I. Edição de P. Ayres. Oxford: Oxford UP, 1999.

${ }^{4}$ DIDEROT, Paradoxo sobre o comediante.

${ }_{5}$ D'ALEMBERT, Essai sur les elements de philosophie, p. 231, apud GOLDSCHMIDT, Écrits - études de philosophie moderne, v. II, p. 101.
} 
ou épocas de corrupção, ao distinguir a pompa da vida da corte à virtude presente nas maneiras simples, Rousseau não estaria fazendo outra coisa senão dar voz a uma tradição compartilhada por muitos de seus contemporâneos.

De fato, quando lembramos que o tema do luxo vem sendo tratado há séculos, que se trata mesmo de um tópico da crítica das artes e dos costumes, não há como negar o acordo de Rousseau com o restante do discurso que se propaga desde a Antiguidade e que ganha forma de um grande debate no século XVIII: a célebre querela do luxo. No primeiro capítulo de seu Desejo e prazer na Idade Moderna, Luiz Roberto Monzani reconstitui a história dessa discussão que animou autores como Voltaire, Fénelon, Bayle, Hume, Adam Ferguson, Saint-Lambert, autor do verbete Luxo da Enciclopédia. Por trás do tema, estão questões como as da molesse e do falso brilho que "envenena toda uma nação", nas palavras de Fénelon ${ }^{6}$, do prazer desregrado e da soberba que corrompe a natureza humana e se opõe à vida sóbria, simples e moderada que tornaria os homens virtuosos. Mesmo aqueles que, como Voltaire e Hume, defendem o luxo e seu papel na promoção de empresas humanas como as artes, ciências e comércio, explica-nos Monzani, não deixarão de ver nele algo de perigoso: há sempre um elemento pernicioso no tema que é preciso destacar e do qual é necessário se afastar. Embora a obra de Rousseau apresente momentos em que seria possível aproximá-lo da postura que um Fénelon assume diante da querela (ou seja, contrária à de Hume e Voltaire, sobretudo nas passagens do Primeiro Discurso em que se defende a virtude marcial de Esparta contra a molesse, a pompa e a vaidade que corrompe a vida social), o próprio fato de Monzani optar por não mencionar o nome do genebrino nas páginas que dedica à querela do luxo já destaca o local ou posição peculiar que Rousseau ocuparia na discussão que então se tratava ${ }^{7}$. Em que medida o pensador genebrino, ao fazer do luxo e da análise dos vícios da sociedade um objeto de reflexão, não acaba por se afastar da célebre querela que anima o seu século, colocando-se numa posição tão ímpar que para o historiador que a reconstitui (a querela), torna-se difícil fazer dele mais um membro do debate? Já nas linhas que compunham o Primeiro Discurso, era possível perceber a distância que Rousseau assumia ao considerar o tema:

\footnotetext{
${ }^{6}$ FÉNELON, Les aventures de Télémaque, apud MONZANI, Desejo e prazer na Idade Moderna, p. 29.

7 Trata-se, como deixa bem claro Monzani na Conclusão de Desejo e prazer na Idade Moderna, de uma escolha metodológica que atende ao modo próprio como seu livro estrutura o tema do luxo no interior de uma "cartografia", se assim podemos dizer ao emprestar um termo empregado pelo autor quando analisa Mandeville (p. 39), cujo fim é o de mapear as questões e os pensadores pelos quais a Idade Moderna relaciona e pensa o par desejo e prazer: "o grande ausente de nosso estudo, em razão do ponto de vista que adotamos" (p. 260), diz-nos essa Conclusão acerca de Rousseau. Ausência não apenas consciente, mas extremamente reveladora, ela nos indica quão distintas e estranhas tendem a ser as posições de Rousseau frente àquelas que seus contemporâneos comumente tomam nos debates que travavam, do qual a querela do luxo é um exemplo.
} 
"Que faríamos das artes sem o luxo que as nutre? Sem as injustiças dos homens, de que serviria a jurisprudência? Que seria da história, se não houvesse nem tiranos, nem guerras ou conspiradores?"8

O que seria da medicina se antes não se tivesse inventado as doenças, também dirá Rousseau no Segundo Discurso? Vemos aqui um modo de tratar o tema do luxo que o vincula diretamente ao surgimento e promoção das artes: "Tal é o luxo", continua Rousseau, "como elas (artes e ciências) nascido da ociosidade e da vaidade dos homens, o luxo

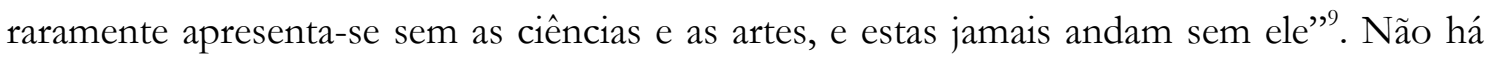
como dissociar a arte e a ciência do luxo, no seu sentido mais pejorativo. Não se trata então de se perguntar pelos malefícios que o luxo pode trazer às artes e ciências, mas de assumir uma posição radical, pela qual não se pode simplesmente separar arte, ciência e luxo. $O$ próprio exercício da arte e da ciência já está relacionado a certa ociosidade que é, desde o princípio, "luxuosa" e maléfica, algo que amolece os homens e os torna tão viciosos quanto falsos, destituídos da virtude marcial robusta e saudável que os aproximaria da natureza:

"De que precisamente se trata, pois, nessa questão do luxo? Trata-se de saber o que é mais importante para os impérios - serem brilhantes e momentâneos, ou virtuosos e duráveis. Digo brilhantes, mas qual o seu brilho?"10

As luzes das artes e das ciências não passariam então de um verniz, mera superficialidade que mais engana do que ilumina. Como comenta Jean Starobinski, no seu célebre estudo sobre Rousseau, ao criticar a sociedade e suas instituições, o genebrino quer se afastar da crítica a elas endereçadas pelos seus contemporâneos, vendo nelas a mera expressão do mal que pretensamente estariam combatendo:

Sua crítica, que se dirige a um mal radical, não quer ter nada em comum com a crítica que os 'filósofos' dirigem contra as instituições abusivas. Pois a crítica dos filósofos ainda não é, aos olhos de Rousseau, senão uma expressão do mal social. Longe de ser o seu inimigo, ela (a crítica dos filósofos) é o produto mais elaborado e mais envenenado; ela trabalha ativamente para o pior. Os 'filósofos' não só não fazem exceção à vaidade, mas tiram proveito desse mundo maléfico que tende à sua própria destruição. $^{11}$

O que fazem os "filósofos" senão cultivar as letras e disseminar a pompa, a vaidade, o vício e o amolecimento dos costumes que delas decorrem? O que faria uma querela do luxo senão fomentar o próprio luxo? "Foi assim que todas as nações, em todos os tempos,

\footnotetext{
${ }^{8}$ ROUSSEAU, Discurso sobre as ciências e as artes, p. 147.

${ }^{9}$ ROUSSEAU, Discurso sobre as ciências $e$ as artes, p. 148.

${ }^{10}$ ROUSSEAU, Discurso sobre as ciências e as artes, p. 149.

${ }^{11}$ STAROBINSKI, Jean-Jacques Rousseau: la transparence et l'obstacle, p. 51.
} 
concordaram em condenar o luxo mesmo quando se entregavam a ele, sem que nenhum Filósofo ousasse contradizer a opinião pública durante uma tão longa série de séculos"12, escreve Rousseau. Cabe aqui atacar, sobretudo, os eruditos, os pretensos sábios e os letrados, assumindo o risco de fazê-lo pelo meio que lhes é próprio: as letras. Sabe-se o quão consciente e, ao mesmo tempo, paradoxal, é a postura que Rousseau assume quando se propõe a criticar as letras tornando-se um escritor. Trata-se literalmente de atacar o mal pela raiz, do ponto em que ele nasce, a partir de onde seria possível compreender todo o seu funcionamento.

Rousseau, lembra-nos Starobinski, nunca deixou de escrever e talvez seja possível afirmar que sem essa condição jamais poderia ter criticado as letras do modo como fez e dirigido ataques tão contundentes à maneira como seus contemporâneos pensavam e escreviam. É como escritor que Rousseau, no Primeiro Discurso, irá examinar uma postura muito comum aos artistas e escritores de seu tempo. Na ânsia de ser aplaudido, o autor busca os "elogios de seus contemporâneos". "O que ele fará, senhores?", pergunta Rousseau. "Rebaixará seu gênio ao nível de seu século e preferirá compor obras comuns, que sejam admiradas durante sua vida, a maravilhas que só serão admiradas muito tempo depois de sua morte". A continuidade do texto nos apresenta um ataque explícito a Voltaire: "Dizei-nos, célebre Arouët, quantas belezas masculinas e fortes não sacrificastes à nossa falsa delicadeza, e quanto o espírito de galanteria, tão fértil em pequenas coisas, não nos custou em grandes coisas?" "13. O "célebre Arouët" é aqui descrito como alguém que, a exemplo dos letrados e gênios de então, concede e nivela o seu gosto pelo de sua época. Sua "celebridade" deve então muito a esse tipo de procedimento em voga que não apenas diminuiria a força e o poder de sua arte, ao rebaixar-se ao nível da referida "falsa delicadeza", mas que também perpetuaria o que há de pior no século: o espírito de galanteria, a falsa eloquência, a linguagem fútil e pomposa da corte, enfim, todas as formas que o luxo assume na época em que Rousseau escreve. Essa crítica às artes, bem como ao modo como os philosophes a pensavam, acentua-se alguns anos mais tarde, em 1758, quando Rousseau lança a Carta a D'Alembert. "Se ele deseja que o levemos a sério", escreve Starobinski, "ele deverá ser muito mais do que um escritor de oposição: ele se vê obrigado a se tornar a oposição viva"

Momento decisivo em sua vida, a Carta a D'Alembert marca o rompimento com o círculo de pensadores e eruditos que escreviam para a Enciclopédia. Como se sabe, o texto é endereçado a um verbete que D’Alembert redigiu para o grande dicionário em que se defendia a liberação do teatro em Genebra. Antes mesmo da publicação do volume da Enciclopédia em que surgiria o verbete Genebra, Rousseau já tinha conhecimento de seu

\footnotetext{
12 ROUSSEAU, Le luxe, le commerce et les arts, p. 518.

${ }^{13}$ ROUSSEAU, Discurso sobre as ciências e as artes, p. 149.

${ }^{14}$ STAROBINSKI, Jean-Jacques Rousseau: la transparence et l'obstacle, p. 52, grifo nosso.
} 
conteúdo: "esperei com impaciência o volume da Enciclopédia no qual estava esse artigo, para ver se não havia um meio de elaborar qualquer resposta que pudesse parar esse lance infeliz (ce malheureux coup) ${ }^{\prime \prime 15}$. Em 10 de outubro de 1757, o artigo de D'Alembert está impresso. Em 20 de dezembro do mesmo ano, Rousseau o tem em mãos. Em março de 1758, ele já havia escrito sua resposta a D’Alembert. Em 2 de outubro de 1758, o texto de Rousseau já está circulando. Muito do teor de indignação que move Rousseau a escrevê-lo pode ser encontrado em uma missiva dirigida ao seu conterrâneo, o Pastor Vernes, citado por Buffat em sua edição da Carta a D'Alembert. Nesta missiva de 4 de julho de 1758, Rousseau diz:

Tenho no prelo um pequeno escrito sobre o artigo 'Genebra' do Sr. D’Alembert. O conselho que ele nos dá para estabelecer uma comédia pareceu-me pernicioso, ele suscitou meu zelo e me indignou tanto que vi claramente que ele não tinha escrúpulos em fazer sua corte ao Sr. De Voltaire às nossas custas. Eis os autores e os filósofos! Sempre tendo por motivo algum interesse particular e o bem público como pretexto! ${ }^{16}$

O que é então o teatro, senão mais uma forma de promover o que Rousseau considera como extremamente pernicioso, isto é: o próprio discurso dos filósofos? Dizer não à entrada do teatro em Genebra era opor-se a todas as ideias expressas pelo grupo da Enciclopédia ou, ao menos, negar o argumento segundo o qual ciências e artes são importantes para o processo civilizatório, que aperfeiçoariam a natureza humana, tornando os homens mais virtuosos. Ao contrário, dirá Rousseau, o teatro não é necessariamente virtuoso e, no caso de Genebra, é perigoso. Antes de tudo, ele nos diz, é preciso lembrar que o teatro faz parte de um conjunto de "instituições"17 sociais mais abrangentes denominadas espetáculos. A grande função e efeito buscados por um espetáculo, ele continua, é o de "reforçar o caráter nacional, acentuar as inclinações naturais e dar energia às paixões"18. Assim, para que se tenha espetáculo, é preciso que haja uma nação e uma tendência ou característica que dê identidade ao seu povo. Toda exibição pública que se faz nesse lugar tem então de estar de acordo com o caráter nacional que $a$ promove e que $a$ faz ter sentido. Por isso, Rousseau nos dirá que perguntar "se os espetáculos são bons ou maus em si mesmos é uma pergunta vaga demais"19. "O homem é uno, admito", escreve Rousseau,

${ }^{15}$ ROUSSEAU, Les Confessions, Livre X, apud BUFFAT, Présentation. In: ROUSSEAU, Lettre à D'Alembert, p. 200.

${ }^{16}$ ROUSSEAU, Correspondance complète, t. V, éd. R. A. Leigh, Genève, Institut Voltaire, p. 106, apud BUFFAT,

Présentation. In: ROUSSEAU, Lettre à D'Alembert, p. 198.

${ }^{17}$ ROUSSEAU, Carta a D'Alembert, p. 39.

${ }^{18}$ ROUSSEAU, Carta a D'Alembert, p. 42.

${ }^{19}$ ROUSSEAU, Carta a D'Alembert, p. 40. 
mas o homem modificado pelas religiões, pelos governos, pelas leis, pelos costumes, pelos preconceitos e pelos climas torna-se tão diferente de si mesmo que agora já não devemos procurar o que é bom para os homens em geral, e sim o que é bom para eles em tal tempo e em tal lugar: assim as peças de Menandro, feitas para o teatro de Atenas, ficavam deslocadas no de Roma $[\ldots] .^{20}$

Não se pode simplesmente transportar uma forma de espetáculo, oriunda de um local ou nação, para outra nação, com costumes e modos distintos, sem que com isso não se descaracterize ou desloque os costumes locais. O que não faria o teatro com Genebra? Muito da corrupção presente no teatro moderno e naqueles que o exercem, sobretudo o comediante, parece estar relacionado ao fato de ser ele uma forma de espetáculo que há muito já perdeu o seu caráter e que vive, por assim dizer, "fora de si mesmo", assumindo as formas mais estranhas, alheias ou alienadas e, por isso, não sendo capaz de provocar senão estranheza, alheamento ou alienação, como nos mostra Bento Prado Jr. ao citar a Carta:

Enfim, seus espetáculos (os dos gregos) nada tinham da mesquinharia dos de hoje em dia. Seus teatros não eram erguidos pelo interesse e pela avareza; não se fechavam em obscuras prisões; os atores não precisavam fazer os espectadores pagarem, nem contar com o rabo do olho as pessoas que viam passar pela porta, para terem certeza do jantar. ${ }^{21}$

No século XVIII e, sobretudo, na França setecentista, o espetáculo foi trancado em uma sala escura em que as individualidades e características de cada um se apagam - em que o espetáculo propriamente dito (o que vemos "aparecer" ou "se mostrar" no palco) se distancia do público que, passivamente, o assiste. Essa simples conformação da cena, nos lembra Bento Prado e também Luiz Roberto Salinas ${ }^{22}$, já nos indica o quanto ela se tornou o representante de um tipo de vida ou de costumes que reinam nesse local e época: um modo de viver pautado pela mesquinharia, no qual a aparência e a ostentação valem mais do que aquilo que se é ou do que se deveria ser. Diferentemente do que ocorre nos espetáculos feitos por povos simples, o que se vê em cidades como Paris apenas promove a desigualdade entre aqueles que tomam parte de semelhante espetáculo:

\footnotetext{
${ }^{20}$ ROUSSEAU, Carta a D'Alembert, p. 40, grifo nosso.

${ }^{21}$ ROUSSEAU, Carta a D'Alembert, p. 91. O trecho é citado por Bento Prado Jr. em "Gênese e estrutura dos espetáculos". In: A retórica de Rousseau, p. 282.

${ }^{22}$ Ver SALINAS FORTES, Paradoxo do espetáculo - política e poética em Rousseau.
} 
“Acreditamos reunir-nos no espetáculo, e é ali que cada um se isola; é ali que vemos esquecer os amigos, os vizinhos, os próximos, para nos interessarmos por fábulas, para chorarmos as desgraças dos mortos ou rirmos às custas dos vivos" ${ }^{\prime 2}$.

É possível detectar a corrupção e o vício do teatro que se faz em Paris pelos sintomas apresentados pelos seus costumes, modas e pelo modo como se constituem suas instituições sociais: o apego à pompa, à soberba, e ao luxo denunciam uma desproporção que é descaracterização ou falta de caráter - é perda de si. Por todos os lados, de várias maneiras, manifesta-se nesse tipo de sociedade, da qual Paris é o paradigma, o que Bento Prado chama de "privatização da vida social" 24 , processo pelo qual as pessoas são cada vez mais desiguais, em que precisam se distinguir, numa tentativa infinita de se sobrepor aos outros, movimento que torna o homem falso e ao qual o Segundo Discurso denomina amorpróprio, muito diferente da bela e simples emulação que reina nos espetáculos feitos por povos virtuosos - nos quais os jogos, competições e torneios, que ocorrem a céu aberto, apenas exaltam e manifestam o espetáculo cívico, como ocorria nas demonstrações públicas espartanas elogiadas pelo Primeiro Discurso e, posteriormente, pela Carta a D'Alembert. "Não é só por seu objetivo, mas também por sua simplicidade que as acho recomendáveis: sem pompa, sem luxo, sem aparato, tudo ali respirava, com um encanto secreto de patriotismo que as tornava interessantes" ${ }^{25}$, escreve o genebrino acerca de tais festas. Se há então uma particularidade ou caráter próprio no modo como Rousseau considera o tema do luxo, talvez esteja na maneira radical (termo que por vezes se emprega para designar suas posições, a exemplo do que faz Starobinski) com que ele o relaciona à defesa de um modo de vida simples, capaz de produzir espetáculos que, no limite, sejam desprovidos de arte e se apresentem de maneira natural, próprios de um povo que, por isso mesmo, já não encena, mas vive o espetáculo sem aparências, longe do claro-escuro que se mostra nas casas de teatro de Paris e sob a luz do céu aberto.

\section{SPECTACLE UNPROVIDED OF ART - THE THEME OF LUXURY IN ROUSSEAU}

Abstract: This article analyzes Rousseau's peculiar attitude in the famous "quarrel of luxury": faced with the valorization of refined taste in Arts in a century marked by the spirit of gallantry and by the court's futile and pompous life model, it is as a writer that Rousseau, paradoxically and consciously, denounces the harmful social effects of luxury on customs.

Keywords: Rousseau, luxury, arts, sciences.

\footnotetext{
${ }^{23}$ ROUSSEAU, Carta a D'Alembert, p. 40.

24 PRADO JR., "Gênese e estrutura dos espetáculos". In: A retórica de Rousseau, p. 314.

${ }^{25}$ ROUSSEAU, Carta a D'Alembert, p. 135.
} 


\section{Referências Bibliográficas}

BUFFAT, M. Présentation. In: ROUSSEAU, J.-J. Lettre à D'Alembert. Paris: Garnier Flammarion, 2003.

DIDEROT, D. "Paradoxo sobre o comediante". In: Diderot Obras II (Estética, Poética e Contos). Tradução de J. Guinsburg. São Paulo: Perspectiva, 2000.

FERGUSON, A. An Essay on the History of Civil Society. Edição de Fania Oz-Salzberger. Cambridge: Cambridge University Press, 2001.

GOLDSCHMIDT, V. Écrits - études de philosophie moderne, v. II (Cap. "Rousseau”). Paris: Vrin, 1984.

MONZANI, L. R. Desejo e prazer na Idade Moderna. Curitiba: Champagnat/PUCPR, 2011.

PRADO JR., B. A retórica de Rousseau e outros ensaios. São Paulo: Cosac Naify, 2008.

ROUSSEAU, J.-J. Discurso sobre as ciências e as artes. São Paulo: Nova Cultural, 1988.

. Discours sur les sciences et les arts. Paris: Gallimard, 1964 (Bibliothèque de la Pléiade, III).

Discurso sobre a origem e os fundamentos da desigualdade entre os homens. São Paulo: Nova Cultural, 1988.

Discours sur l'origine et les fondements de l'inégalité parmi les hommes. Paris: Gallimard, 1964 (Bibliothèque de la Pléiade, III). 1993.

Carta a D'Alembert. Tradução de Roberto Leal Ferreira. Campinas: Ed. Unicamp,

Lettre à D'Alembert. Paris: Gallimard, 1995 (Bibliothèque de la Pléiade, V).

Le luxe, le commerce et les arts. Paris: Gallimard, 1964 (Bibliothèque de la Pléiade, III).

SALINAS FORTES, L. R. Paradoxo do espetáculo - política e poética em Rousseau. São Paulo:

Discurso Editorial, 1997.

SHAFTESBURY. Soliloquy, or Advice to an Author. In: Characteristicks of Men, Manners,

Opinions, Times, v. I. Edição de P. Ayres. Oxford: Oxford UP, 1999.

STAROBINSKI, J. Jean-Jacques Rousseau: la transparence et l'obstacle. Paris: Gallimard, 2006. 